\title{
Derivation of a Mortal Injury Metric for Studies of Rapid Decompression of Depth-Acclimated Physostomous Fish
}

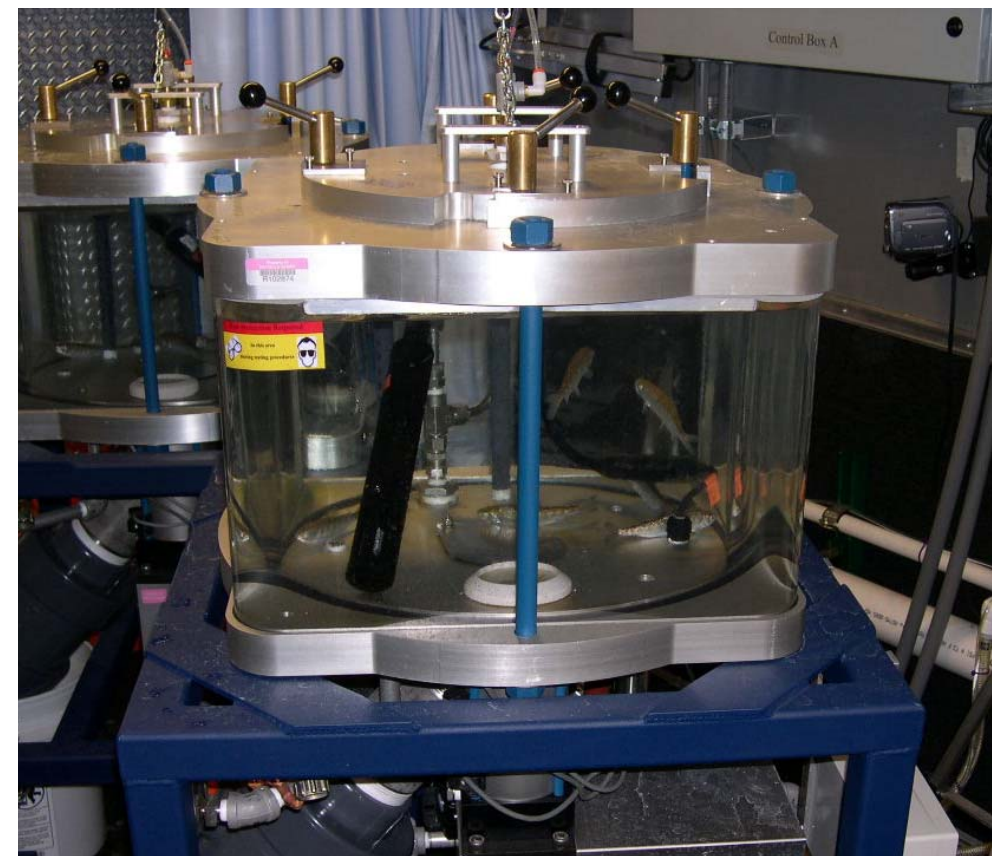

C. McKinstry

T.J. Carlson

R.S. Brown

Final Report

November 2007

Prepared for the U.S. Army Corps of Engineers

Portland District, Portland, Oregon

Under a Related Services Agreement

with the U.S. Department of Energy

Contract DE-AC05-76RL01830

\section{Pacific Northwest \\ National Laboratory}

Operated by Battelle for the

U.S. Department of Energy 


\title{
DISCLAIMER
}

This report was prepared as an account of work sponsored by an agency of the United States Government. Neither the United States Government nor any agency thereof, nor Battelle Memorial Institute, nor any of their employees, makes any warranty, express or implied, or assumes any legal liability or responsibility for the accuracy, completeness, or usefulness of any information, apparatus, product, or process disclosed, or represents that its use would not infringe privately owned rights. Reference herein to any specific commercial product, process, or service by trade name, trademark, manufacturer, or otherwise does not necessarily constitute or imply its endorsement, recommendation, or favoring by the United States Government or any agency thereof, or Battelle Memorial Institute. The views and opinions of authors expressed herein do not necessarily state or reflect those of the United States Government or any agency thereof.

\author{
PACIFIC NORTHWEST NATIONAL LABORATORY \\ operated by \\ BATTELLE \\ for the \\ UNITED STATES DEPARTMENT OF ENERGY \\ under Contract DE-AC05-76RL01830
}

Printed in the United States of America
Available to DOE and DOE contactors from the Office of Scientific and Technical Information, P.O. Box 62, Oak Ridge, TN 37831-0062;
ph: (865) 576-8401
fax: (865) 576-5728
email: reports@adonis.osti.gov

\begin{abstract}
Available to the public from the National Technical Information Service, U.S. Department of Commerce, 5285 Port Royal Rd., Springfield, VA 22161 ph: (800) 553-6847 fax: (703) 605-6900 email: orders@ntis.fedworld.gov online ordering: http://www.ntis.gov/ordering.htm
\end{abstract}




\title{
Derivation of a Mortal Injury Metric for Studies of Rapid Decompression of Depth-Acclimated Physostomous Fish
}

\author{
C. McKinstry \\ T.J. Carlson \\ R.S. Brown
}

Final Report

November 2007

Prepared for the U.S. Army Corps of Engineers

Portland District, Portland, Oregon

Under a Related Services Agreement

with the U.S. Department of Energy

Contract DE-AC05-76RL01830

Pacific Northwest National Laboratory

Richland, Washington 99354 



\section{Executive Summary}

In 2005 the U.S. Army Corps of Engineers (USACE) began a study to investigate the response of hatchery and run-of-the-river juvenile Chinook salmon to the effects of rapid decompression during passage through mainstem Federal Columbia River Power System (FCRPS) Kaplan turbines. In laboratory studies conducted by Pacific Northwest National Laboratory (PNNL) for USACE since 2005, juvenile fish have been exposed to rapid decompression in barometric pressure chambers.

An initial study considered the response of juvenile Chinook salmon bearing radio transmitters to rapid decompression resulting from exposure to a pressure time history simulating the worst case condition that might be experienced during passage through an operating turbine. The study in 2005 found that acclimation depth was a very important treatment factor that greatly influenced the significantly higher incidence of injury and mortality of rapidly decompressed Chinook salmon bearing radio telemetry devices.

In 2006 we initiated a statistical investigation using data in hand into derivation of a new end-point measure for assessment of the physiological response of juvenile Chinook salmon to rapid decompression. Our goal was a measure that would more fully utilize both mortality and injury data while providing a better assessment of the most likely survival outcome for juvenile physostomous fish exposed to rapid decompression.

The conclusion of the analysis process was to classify fish as mortally injured when any of the eight injuries are present, regardless of whether the fish was last observed alive or not. The mortally injured classification has replaced mortality as the end point metric for our rapid decompression studies. The process described in this report is an example of how a data set may be analyzed to identify decision criterion for objective classification of test fish to a specific end-point. The resulting list of eight mortal injuries is applicable to assess injuries from rapid decompression and is currently being applied to ongoing studies. We intend to update this analysis as more data become available and to extend it to runof-river Chinook salmon smolts. The method itself is applicable to other injury and mortality data for juvenile salmonids from laboratory and field studies related to all dam passage routes and for collision, strike, and shear injuries in addition to decompression. 


\section{Acknowledgments}

Funding for this project was provided by the U.S. Army Corps of Engineers, Portland District. Michael Langeslay was the contracting office technical representative. 


\section{Contents}

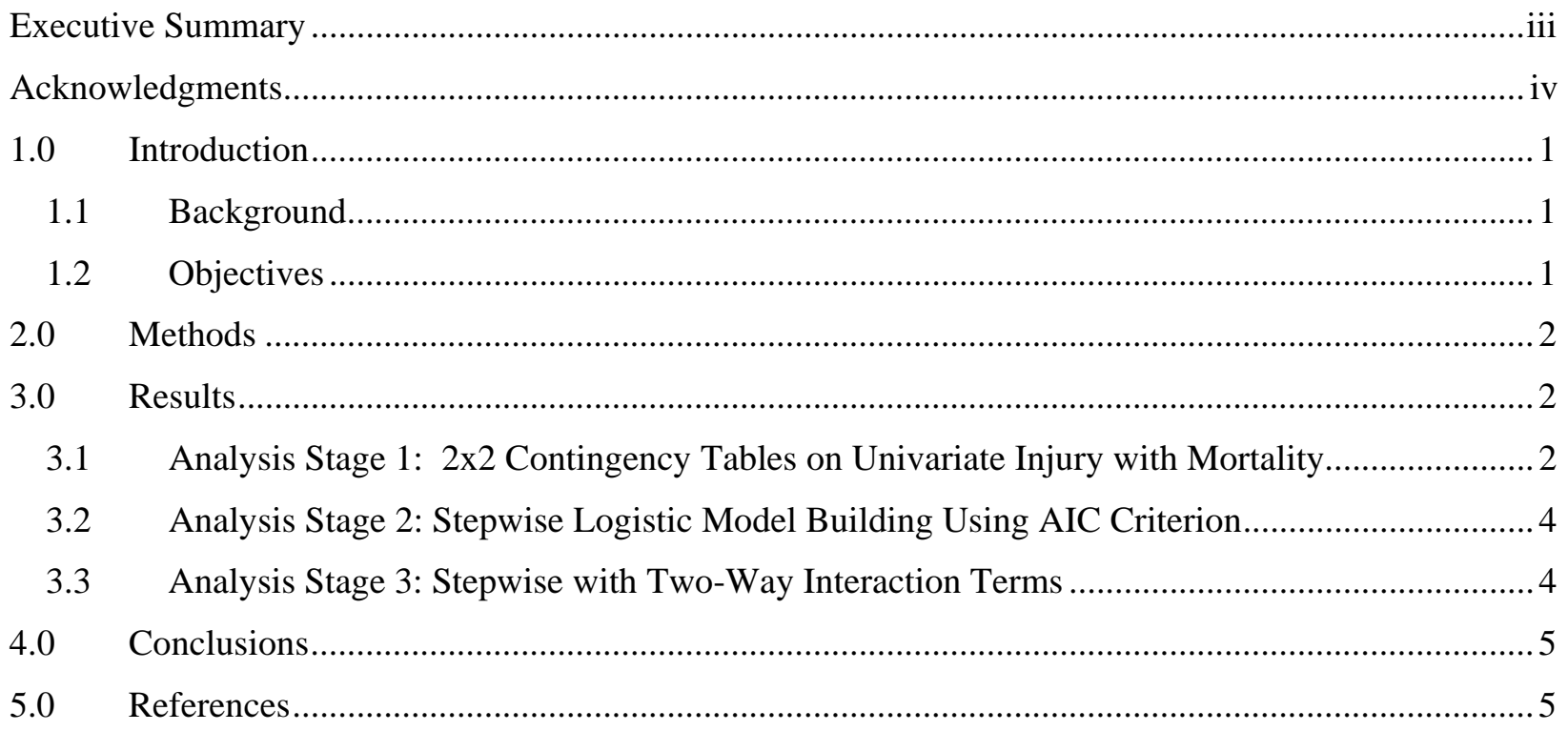

\section{Tables}

Table 1. 2x2 Contingency Tables with Mortality …............................................................................... 2

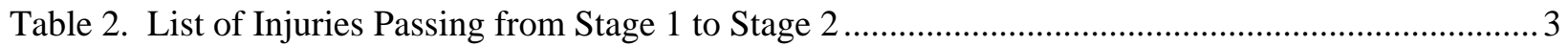


Derivation of Mortal Injury Metric for Rapid Decompression of Depth-Acclimated Physostomous Fish 


\subsection{Introduction}

\subsection{Background}

In 2005 the U.S. Army Corps of Engineers (USACE) began a study to investigate the response of juvenile Chinook salmon to rapid decompression during passage through Kaplan turbines to mainstem dams in the Federal Columbia River Power System (FCRPS). Since 2005 Pacific Northwest National Laboratory (PNNL) has conducted several laboratory studies for USACE involving exposing juvenile fish to rapid decompression in barometric pressure chambers. An initial study considered the response of juvenile Chinook salmon that had been implanted with radio transmitters. The salmon were exposed to rapid decompression using pressure changes that were designed to simulate the worst case condition that fish might experience during passage through an operating turbine (Brown et al. 2007). This study, and those that followed, are unique because, in addition to other treatment factors, exposures were performed on physostomous fish that had been allowed to become neutrally buoyant at pressures simulating the depths at which they are commonly observed. In addition, test fish were simultaneously acclimated to total dissolved gas levels that occur during juvenile salmon downstream migrations.

The study in 2005 found that acclimation depth was a very important treatment factor that greatly influenced the significantly higher incidence of injury and mortality of rapidly decompressed Chinook salmon bearing radio telemetry devices (Brown et al. 2007). In this study, fish were held for 48 hours post-exposure to observe recovery from rapid decompression and to assess delayed mortality. However, in subsequent studies, juvenile salmon have not been held post-exposure because of uncertainty in how to simulate ambient river conditions during the holding period, particularly how to simulate the relationship between depth of occurrence and total dissolved gas that turbine-passed fish would experience post passage. In the first of these studies, necropsy and histological examination of fish alive at the end of the exposure showed injuries that, in our opinion, physiologically would compromise their short-term, much less long-term survival. We also felt that we were not making optimum use of all of the data we were acquiring, particularly fish injury data.

\subsection{Objectives}

In 2006 we used existing data to initiate a statistical investigation into derivation of a new end-point measure for assessment of the physiological response of juvenile Chinook salmon to rapid decompression. Our goal was a measure that would more fully utilize both mortality and injury data while providing a better assessment of the most likely survival outcome for juvenile physostomous fish exposed to rapid decompression.

In this report we set out to explain the analysis we conducted to identify the injury types that would be included in our new mortal injury endpoint for study of rapid decompression of juvenile Chinook salmon. 


\subsection{Methods}

The following sections describe the statistical process used to reduce a large set of fish injuries to a smaller set most predictive of mortality in juvenile Chinook salmon subjected to rapid decompression in a controlled laboratory study. The study protocol for rapid decompression exposure had fish acclimate in a vessel pressurized to a specific depth-equivalent pressure in water with specific total dissolved gas content (TDG). Following acclimation, test fish were subjected to rapid decompression to a nadir pressure. The pressure nadir and rate of change in pressure (ROC) immediately prior to the nadir were recorded. Following exposure, test fish were immediately removed from the vessel and assessed as alive or dead within 10 minutes of the test. Those still alive were euthanized before necropsies were performed on all test fish. Presence/absence determinations were made for 45 different injuries during necropsy. The statistical process described here follows three analysis stages that progressively eliminated injuries at each stage to arrive at a final set found to be most predictive of mortality in the test fish.

\subsection{Results}

\subsection{Analysis Stage 1: $2 \times 2$ Contingency Tables on Univariate Injury with Mortality}

Odds-ratios and Fisher's exact test (Agresti 1990) results were assessed from 2x2 contingency tables on each of the 45 observed injuries with observed mortality. In Table 1 "Emboli in Gills" is used as an example of an injury that passes statistical assessment and is included in the injury list for additional analysis while "Bruising of the pericardium" fails statistical criterion for additional analysis.

Table 1. 2x2 Contingency Tables for Two Injury Types with Mortality.

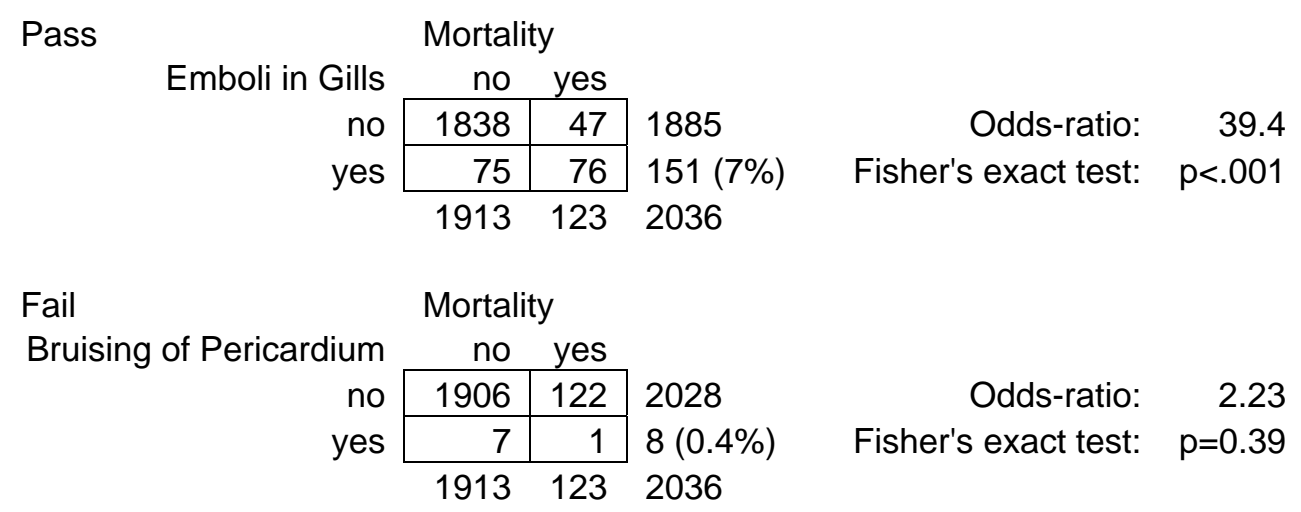


The two contingency tables in Table 1 each cross-classify the 2036 total test fish as those observed dead or alive within 10 minutes of the test with those observed in the necropsy with or without the specified injury. The cell counts in each table are used to compute a summary statistic called the oddsratio. The odds ratio is used in Fisher's exact test of whether having the injury is associated with an increased chance of mortality. An odds-ratio with value one (1) indicates no evidence that fish having the injury are more likely to die than fish not having it. Odds-ratios that exceed one and become increasingly large suggest an increasing likelihood of mortality in fish having the injury. The p-value of Fisher's exact test gives the statistical significance, or strength of evidence, of the odds-ratio.

In the example, Emboli in the Gills show a 7\% occurrence rate, with an odds-ratio of 39.4 and a highly significant p-value from Fisher's exact test. On the other hand, bruising of the pericardium shows only a $0.4 \%$ occurrence rate and a non-significant odds ratio. Thus Emboli in the Gills is retained into analysis Stage 2, while Bruising of the Pericardium is not. The final result from analysis Stage 1 was that 22 of the original 45 injuries were retained for analysis Stage 2, as is shown in Table 2.

Table 2. List of Injuries Passing from Stage 1 to Stage 2. Also shown are the odds ratio, confidence limits for the odds ratio, and the Fisher's exact test level of significance for the occurrence of the injury in fish that are mortally injured during rapid decompression.

\begin{tabular}{|c|c|c|c|c|c|}
\hline & Injury & $\begin{array}{l}\text { Odds } \\
\text { Ratio }\end{array}$ & $\begin{array}{l}\text { Lower } \\
95 \% \mathrm{Cl}\end{array}$ & $\begin{array}{l}\text { Upper } \\
95 \% \mathrm{Cl}\end{array}$ & $\begin{array}{c}\text { Fisher's Exact } \\
\text { p-Value }\end{array}$ \\
\hline 1 & Emboli in the gills & 39.4 & 25.2 & 62.3 & $2.0 \mathrm{E}-62$ \\
\hline 2 & Emboli in the pectoral fins & 21.1 & 13.2 & 34.0 & $1.8 \mathrm{E}-34$ \\
\hline 3 & Hemorrhaging in the pericardium & 28.3 & 16.6 & 49.0 & $2.4 \mathrm{E}-33$ \\
\hline 4 & Swim bladder rupture & 15.3 & 7.7 & 34.5 & $2.4 \mathrm{E}-27$ \\
\hline 5 & Emboli in the pelvic fins & 16.1 & 9.5 & 27.0 & $1.8 \mathrm{E}-23$ \\
\hline 6 & Hemorrhaging in the liver & 9.3 & 6.1 & 14.2 & 4.0E-23 \\
\hline 7 & Exothalmia (eye-pop) & 16.3 & 9.3 & 28.4 & $1.3 \mathrm{E}-20$ \\
\hline 8 & Emboli in the dorsal fin & 15.6 & 8.8 & 27.3 & $1.2 \mathrm{E}-19$ \\
\hline 9 & Emboli in the right eye & 13.8 & 7.8 & 24.4 & 1.6E-17 \\
\hline 10 & Hemorrhage in the right eye & 5.8 & 3.8 & 8.8 & $3.5 \mathrm{E}-16$ \\
\hline 11 & Emboli in the left eye & 11.9 & 6.6 & 21.1 & $2.7 \mathrm{E}-15$ \\
\hline 12 & Emboli in the anal fin & 11.1 & 6.3 & 19.3 & $2.8 \mathrm{E}-15$ \\
\hline 13 & Hemorrhage in the left eye & 4.9 & 3.2 & 7.4 & $5.0 \mathrm{E}-13$ \\
\hline 14 & Hemorrhage in intestines & 5.0 & 3.2 & 7.9 & 3.5E-11 \\
\hline 15 & Emboli in the kidney & 4.0 & 2.6 & 6.0 & $5.8 \mathrm{E}-11$ \\
\hline 16 & Blood or bile secretions from the vent & 7.8 & 3.7 & 15.6 & $1.4 \mathrm{E}-07$ \\
\hline 17 & Hemorrhaging in the kidney & 5.7 & 2.8 & 11.1 & 2.8E-06 \\
\hline 18 & Hemorrhage in the pectoral fin & 3.6 & 2.1 & 6.0 & $3.4 \mathrm{E}-06$ \\
\hline 19 & Emboli in the pericardium & 11.9 & 1.7 & 71.2 & $6.3 \mathrm{E}-03$ \\
\hline 20 & Renal capillary hemorrhaging & 0.6 & 0.4 & 0.9 & 1.1E-02 \\
\hline 21 & Hemorrhage in the pelvic fin & 2.7 & 0.9 & 6.8 & $3.4 \mathrm{E}-02$ \\
\hline 22 & Hemorrhage in the anal fin & 3.2 & 0.8 & 9.7 & $5.3 \mathrm{E}-02$ \\
\hline
\end{tabular}




\subsection{Analysis Stage 2: Stepwise Logistic Model Building Using AIC Criterion}

Model building is the process of selecting a best subset of predictor variables in a regression model from a larger set. The stepwise model building procedure is an automated way of selecting predictor variables through a sequence of steps. At each step, a model parameter is either added or dropped from the current model and the resulting model is compared to the model in the previous step based on a change in the value of the Akaike Information Criterion (AIC) (Hosmer and Lemeshow 2000; Venables and Ripley 2000). The AIC is a goodness-of-fit measure of an estimated statistical model and was used to determine the "best" subset of variables (1).

$$
A I C=2 k-2 \ln (L)
$$

In equation (1), $k$ is the number of parameters (a.k.a. independent predictor variables) in the logistic regression model, and $L$ is the value of the likelihood function. When comparing two models, the model with the smaller AIC is better. As formulated in equation(1), the AIC penalizes for more model terms (larger $k$ ) while it rewards for larger values of the likelihood function $(L)$ indicating better model fit. The AIC gives a concise measure of model "parsimony" where simpler models having fewer model terms are favored over more complex models. Adding more model terms (increasing $k$ ) will always increase (or at least never decrease) the value of the likelihood term in the AIC, but comes at the cost of greater model complexity. The AIC is an operational way of trading off the complexity of a model against goodness of fit.

While injuries were considered one at a time in analysis Stage 1, analysis Stage 2 also considers pair wise correlations between injuries (i.e., main-effects model terms) in arriving at the best subset of variables. The 22 injuries retained from Stage 1 (Table 2) were fit together to a logistic regression model taking a $0 / 1$ binary of mortality as the response variable. The fitted model was then subjected to a stepwise process as described, which, in the end, retained eight injury main effects in the final model:

1. Hemorrhaging in the pericardium

2. Hemorrhaging in the liver

3. Hemorrhaging in the kidney

4. Ruptured swim bladder

5. Exothalmia (eye-pop)

6. Blood or bile secretions from the vent

7. Emboli in the gills

8. Emboli in the pelvic fins.

\subsection{Analysis Stage 3: Stepwise with Two-Way Interaction Terms}

The eight injuries listed above were next fit to another logistic regression model, along with all 28 possible two-way interaction terms. This stage addresses the possibility that one or more of the eight main effects injuries are only important when they occur in combination with another injury. Should that be the case, the stepwise selection process would drop the main effect (injury) term out of the model, and that variable would be included only in interaction term(s) retained in the final best model for analysis 
Stage 3. However, the analysis determined that all eight main effects injury terms should be retained, rendering the interactions no longer relevant. The eight main effect injuries (listed above) were then reviewed by project biologists who concurred with their selection.

\subsection{Conclusions}

The analysis process resulted in classification of fish as mortally injured if any of the eight injuries were present, regardless of whether the fish was observed as alive." As a result of this process, the term "mortally injured" is now used as the end point metric (rather than "mortality" for our rapid decompression studies.

The process described in this report is an example of how a data set may be analyzed to identify decision criterion for objective classification of test fish to a specific end-point. The resulting list of eight mortal injuries is applicable to assess injuries from rapid decompression and is currently being applied to ongoing studies. We intend to update this analysis as more data becomes available and to extend it to runof-river Chinook salmon smolts. The method itself is applicable to other injury and mortality data for juvenile salmonids from laboratory and field studies related to all dam passage routes and for collision, strike, and shear injuries in addition to decompression.

\subsection{References}

Agresti, A. 1990. Categorical Data Analysis. New York: Wiley. Pages 59-66.

Brown, R.S., T.J. Carlson, A.E. Welch, J. R. Stephenson, C.S. Abernethy, C.A. McKinstry, and M.H. Theriault. 2007. Assessment of Barotrauma Resulting from Rapid Decompression of Depth Acclimated Juvenile Chinook Salmon Bearing Radio Telemetry Transmitters. PNNL-16790. Report to the U.S. Army Corps of Engineers, Portland District, Portland, Oregon.

Hosmer, D.W. and S. Lemeshow. 2000. Applied Logistic Regression 2nd Ed. Wiley Series in Probability and Statistics. John Wiley \& Sons, Inc. NewYork.

Venables, W.N. and B.D. Ripley. 2000. Modern Applied Statistics with S-plus 3rd Ed. Springer-Verlag Inc., New York. 


